DOI: 10.4274/gulhane.galenos.2019.724

Gulhane Med J 2020;62:57-9

\title{
A rare case of multiple fibro-folliculomas and lung cysts: Possible Birt-Hogg-Dube syndrome
}

\author{
(1) Ulviyya Gasimova ${ }^{1}$, (1) Salaheldin Elhamamsy ${ }^{2}$, (1) Sam Joseph ${ }^{3}$, (1) Ali Alkhayat ${ }^{4}$ \\ ${ }^{1}$ Nardone Medical Associates, Department of Primary Care, Rhode Island, USA \\ 2Brown University Alpert Medical School, Rhode Island, USA \\ ${ }^{3}$ Saint Mary Medical Center, Langhorne, Philadelphia, USA \\ ${ }^{4}$ Kent Hospital, Rhode Island, USA
}

Date submitted:

12.07.2019

Date accepted:

21.10.2019

Online publication date:

15.03.2020

\section{Corresponding Author:}

Ulviyya Gasimova MD, Nardone

Medical Associates, Department of

Primary Care, Rhode Island, USA

ugasimova@gmail.com

ORCID:

orcid.org/0000-0001-8879-2070

Keywords: Autosomal disease, lung cyst, folliculomas, skin lesion, renal cyst

\begin{abstract}
Birt-Hogg-Dubè syndrome (BHD) is an autosomal-dominant syndrome, which is very rare to come across with in clinical practice. The disease demonstrates itself with multiple skin hamartomas, multiple fiber-folliculomas, and lung cysts with possible involvement of other organs and systems. The purpose to present this case report is to draw an attention to the possibility of BHD syndrome in patients who come to the hospital with multiple lesions and cysts of various localizations. For this purpose, we present the case report of a 75-year-old patient who presented to the clinic with multiple skin lesions on the face, abdomen and back. Multiple thin-walled cysts scattered throughout the both lungs were discovered during further investigation. The patient had the perilous medical history of hypertension and hyperlipidemia, as well as recent history of prominent cough.
\end{abstract}

\section{Introduction}

Birt-Hogg-Dubè (BHD) syndrome, also called HornsteinKnickenberg syndrome, was first described in 1977 (1). It is a rare autosomal dominant disease that is characterized by multiple fibro-folliculomas on the skin, lung cysts that predispose to spontaneous pneumothorax, and increased risk of renal cancer $(2,3)$. BHD syndrome is caused by loss-of-function mutation in the folliculin, also known as FLCN gene found on chromosome $17 p 12-q 11.2$ that encodes for the protein folliculin. Folliculin is expressed in a variety of tissues including the skin, lungs and kidneys. The prevalence of BHD is about $1 / 200,000$ although it is believed that this has been underestimated because of the wide phenotypic interfamilial variability. Less than 300 families have been described to date in the literature and the incidence has been the same for both sexes (4).

\section{Presentation of Case}

A 75-year-old white Afro-American male with a history of smoking visited Nardone Medical Associates for the complaint of cough. The patient also had a history of hypertension and hyperlipidemia. On more detailed physical examination, the patient was found to have multiple skin lesions on the face, abdomen and back. The patient could not recall any similar findings in his first degree family members. Because of his recent complaint of cough and the smoking history, low dose computed tomography (CT) of chest was ordered. On the sixth 
of June 2016, a CT of the lung without intravenous contrast revealed upper lobe predominant centrilobular and paraseptal emphysema. In addition, there were multiple thin-walled cysts scattered throughout both lungs. Calcified granulomas and perifissural lymphoid aggregates were also present. No suspicious granules were found. The CT of the chest also showed mild coronary calcification and scattered mediastinal and hilar nodes, the largest of which measured $1 \mathrm{~cm}$. Limited upper abdominal view revealed renal lesion as well.

A more detailed CT of the abdomen and pelvis with contrast was ordered on June 15, 2016. The image showed multiple bilateral benign renal cysts and unhanged thin walled pulmonary cysts at the lung bases.

The imaging findings and the skin manifestations were strongly indicating BHD syndrome. The patient was referred to the dermatologist and biopsy of the skin lesions was obtained.

The biopsy results came back ambiguous, as so the pathological evaluation of the skin lesions neither proved nor denied the diagnosis.

The results of pathological evaluation of the lung nodules specimen were ambiguous regarding the presence of BHD, as well.

Although the clinical presentation of the patient was strongly indicating the presence of a rare autosomal-dominant disease, the diagnosis was not proved diagnostically based on a genetic testing for the detection of mutation in FLCN gene.

\section{Discussion}

BHD syndrome is a multi-organ, autosomal dominant disorder and was initially described as a dermatologic syndrome. The classic triad present on the skin consists of hamartomas of the hair follicles (fibrofolliculomas), which is the most characteristic clinical finding, tumors of the hair disc (trichodiscomas) and skin tags (acrohondrons). Skin changes typically appear in the third to fourth decades of life. These cutaneous, benign tumors are multiple, skin colored, dome shaped and are more prevalent on face, neck and upper trunk $(5,6)$. Mutations that cause premature protein termination in the $F L C N$ gene and are the cause of the BHD syndrome are also associated with lung cysts, spontaneous pneumothorax, and renal cancer (4). Pulmonary involvement is present in more than $80 \%$ of patients with BHD that manifests as multiple bilateral cysts that increase the risk of recurrent spontaneous pneumothorax 50 times compared to healthy individuals. The median age of pneumothorax is estimated to be around the age of 38 years $(3,7,8)$. The distinguishable feature between BHD syndrome and other known cystic lung diseases is the presence of cysts predominantly in the lower lung, which vary in size and shape $(9,10)$.

Renal cancer occurs at a mean age of 50.7 years although other cases report an earlier onset (3). The risk for renal malignancies in affected individuals is 7 times more compared to those not affected $(8,11)$. Renal cell carcinoma (RCC) appears to be multiple with bilateral lesions presenting in the surrounding parenchyma. The histology of those lesions that are related to BHD syndrome is similar to chromophobe RCC. This is a differentiating factor between BHD syndrome and other syndromes with renal involvement, e.g Von Hippel-Lindau disease that presents with renal tumors of clear histology (12). Involvement of other organs has been suspected to be associated with BHD, such as parathyroid adenomas, angiolipomas, lipomas, parotid oncocytoma (13), colon cancer, and breast cancer but these presentations may be incidental or associated with other syndromes $(12,14)$.

Given the life threatening complications of BHD syndrome, early detection and diagnosis of the disease are important. Menko et al. (2) proposed diagnostic criteria for BHD syndrome.

Major criteria consist of:

- At least five fibrofolliculomas, at least one of which is confirmed histologically and,

- FLCN mutation.

While minor criteria are:

- Multiple bilateral cysts on the base of the lungs,

- A first degree relative with BHDS and,

- Renal cancer of early onset $-<50$ y/o (15).

Patients with BHD are at increased risk for renal neoplasia and may benefit from periodic surveillance. Similarly, family members should be screened and offered genetic counseling. BHD syndrome is a rare disorder and may be under-recognized because of the great variability in clinical expression (2).

\section{Ethics}

Informed Consent: The patient gave an informed consent to publish the case report without revealing his identity, which was followed.

Peer-review: Externally peer-reviewed.

\section{Authorship Contributions}

Surgical and Medical Practices: S.E., Concept: U.G., Design: U.G., S.J., Data Collection or Processing: U.G., S.J., A.A., Analysis or Interpretation: U.G., Literature Search: U.G., S.J., Writing: U.G., S.J., A.A.

Conflict of Interest: No conflict of interest was declared by the authors.

Financial Disclosure: The authors declared that this study received no financial support.

\section{References}

1. Happle R. Hornstein-Birt-Hogg-Dubé syndrome: a renaming and reconsideration. Am J Med Genet A. 2012;158:12471251. 
2. Menko FH, van Steensel MA, Giraud S, et al. Birt-HoggDubé syndrome: diagnosis and management. Lancet Oncol. 2009;10:1199-1206.

3. Pavlovich CP, Walther MM, Eyler RA, Hewitt SM, Zbar B, Linehan WM, Merino MJ. Renal tumors in the Birt-HoggDubé syndrome. Am J Surg Pathol. 2002;26:1542-1552.

4. Schmidt LS, Linehan WM. Molecular genetics and clinical features of Birt-Hogg-Dubé syndrome. Nat Rev Urol. 2015;12:558-569.

5. Ubogy-Rainey Z, James WD, Lupton GP, Rodman OG. Fibrofolliculomas, trichodiscomas, and acrochordons: the Birt-Hogg-Dubé syndrome. J Am Acad Dermatol. 1987;16:452-457.

6. Adley BP, Smith ND, Nayar R, Yang XJ. Birt-HoggDubé syndrome: clinicopathologic findings and genetic alterations. Arch Pathol Lab Med. 2006;130:1865-1870.

7. Toro JR, Wei MH, Glenn GM, et al. BHD mutations, clinical and molecular genetic investigations of Birt-Hogg-Dubé syndrome: a new series of 50 families and a review of published reports. J Med Genet. 2008;45:321-331.

8. Zbar B, Alvord WG, Glenn G, et al. Risk of renal and colonic neoplasms and spontaneous pneumothorax in the Birt-Hogg-Dubé syndrome. Cancer Epidemiol Biomarkers Prev. 2002;11:393-400.
9. Agarwal PP, Gross BH, Holloway BJ, Seely J, Stark P, Kazerooni EA, Thoracic CT findings in Birt-Hogg-Dubè syndrome. AJR Am J Roentgenol. 2011;196:349-352.

10. Butnor KJ, Guinee DG Jr. Pleuropulmonary pathology of Birt-Hogg-Dubé syndrome. Am J Surg Pathol. 2006;30:395399.

11. Palmirotta R, Savonarola A, Ludovici G, et al. Association between Birt Hogg Dubè syndrome and cancer predisposition. Anticancer Res. 2010;30:751-757.

12. Klomp JA, Petillo D, Niemi NM, et al. Birt-Hogg-Dubé renal tumors are genetically distinct from other renal neoplasias and are associated with up-regulation of mitochondrial gene expression. BMC Med Genomics. 2010;3:59.

13. Maffé A, Toschi B, Circo G, et al. Constitutional FLCN mutations in patients with suspected Birt-Hogg-Dubé syndrome ascertained for non-cutaneous manifestations. Clin Genet. 2011;79:345-354.

14. Liaw D, Marsh DJ, Li J, et al. Germline mutations of the PTEN gene in Cowden disease, an inherited breast and thyroid cancer syndrome. Nat Genet. 1997;16:64-67.

15. Le Guyadec T, Dufau JP, Poulain JF, Vaylet F, Grossin M, Lanternier G. Multiple trichodiscomas associated with colonic polyposis. Ann Dermatol Venereol. 1998;125:717719. 